\title{
Evaluation of thyroid dysfunction in patients with menstrual disorders of reproductive age group: a prospective cross-sectional study
}

\author{
Anupma Kumari ${ }^{1 *}$, Renu Rohatgi ${ }^{2}$, Amrita $\operatorname{Singh}^{3}$
}

\author{
${ }^{1}$ Department of Obstetrics and Gynecology, RIMS, Ranchi, Jharkhand, India \\ ${ }^{2}$ Department of Obstetrics and Gynecology, NMCH Patna, Bihar, India \\ ${ }^{3}$ Department of Obstetrics and Gynecology, LHMC, New Delhi, India
}

Received: 08 December 2020

Accepted: 13 January 2021

\section{*Correspondence:}

Dr. Anupma Kumari,

E-mail: anupma.anmmch@gmail.com

Copyright: (c) the author(s), publisher and licensee Medip Academy. This is an open-access article distributed under the terms of the Creative Commons Attribution Non-Commercial License, which permits unrestricted non-commercial use, distribution, and reproduction in any medium, provided the original work is properly cited.

\begin{abstract}
Background: Thyroid disorders specifically the hypothyroidism has been associated with menstrual disturbances in women of reproductive age group. The objective of this study was to estimate the prevalence of thyroid dysfunction and its correlation with menstrual disorders in women of reproductive age group.

Methods: A hospital based prospective analytical study was carried out in the department of Obstetrics and Gynaecology of Nalanda Medical College and Hospital, Patna from March 2017 to March 2018. 56 women of reproductive age group between 18 to 45 years presenting with menstrual disorders (like menorrhagia, oligo/hypomenorrhea, polymenorrhea, metrorrhagia, and amenorrhea) were recruited in this study. Thyroid function test was done in all patients. Statistical analysis done.

Results: Maximum number of patients were seen in the age group of 31-40 years. Most common menstrual complain was menorrhagia (46.42\%) followed by hypo/oligomenorrhoea (17.86\%). In patients with menstrual disorders, 41.07 $\%$ had thyroid disorders in which subclinical hypothyroidism was prevalent in $17.86 \%$, overt hypothyroidism in $12.5 \%$, and overt hyperthyroidism in $5.35 \%$ of the women. Menorrhagia was the commonest menstrual disorder (52.94\%) seen in hypothyroid patients followed by polymenorrhoea. A high degree positive correlation was observed between thyroid dysfunction and menstrual disorder (Pearson correlation coefficient, $r=0.93$ ).

Conclusions: Our study concluded that thyroid dysfunction should be considered as an important etiological factor for menstrual irregularity. Thus, thyroid function tests should be performed in all patients with menstrual irregularities to avoid unnecessary interventions like curettage and hysterectomy.
\end{abstract}

Keywords: Hypothyroidism, Menstrual disorders, Reproductive age women, Thyroid dysfunction

\section{INTRODUCTION}

Menstrual disorders are common problem among women in the reproductive age and pose a huge burden on gynecology OPD, accounting for approximately $20 \%$ of attendance. ${ }^{1}$ These causes significant social embarrassment, affects quality of life and productivity, imposes financial burden and also leads to surgical interventions like hysterectomy. ${ }^{2}$ Thyroid hormones have important role in normal reproductive physiology both by directly effecting the ovaries and indirectly by interacting with sex hormone-binding globulin. ${ }^{3}$ Thyroid disorders are commoner in women than in men and leads to abnormal sexual development, menstrual disorders, infertility and premature menopause. In India, thyroid disorders are among the most common endocrine diseases. ${ }^{4}$ Incidence of thyroid disorders increases with age, and about $26 \%$ of premenopausal and menopausal women are having one or other type of thyroid disease. ${ }^{5}$ Menstrual abnormality precedes the onset of clinically 
overt hypothyroidism or hyperthyroidism. ${ }^{6}$ Hypothyroidism is associated with various reproductive disorders like abnormal sexual development, menstrual irregularities and infertility. ${ }^{1}$ Subclinical hypothyroidism is associated with occult menorrhagia (mild disturbances in menstrual amount and duration) before becoming symptomatic. $^{7}$

The prevalence of subclinical hypothyroidism is as high as $9.5 \%$ in women. ${ }^{8}$ Hyperthyroidism causes delayed onset of menses when occurring before puberty. Oligomenorrhea and amenorrhea are the commonest abnormalities associated with hyperthyroidism in reproductive age group women. ${ }^{9}$ Also thyroid autoimmunity is associated with various kinds of thyroid dysfunction. ${ }^{10}$

Timely detection of thyroid disorders in patients presenting with menstrual disorder and their management can prevent surgical interventions like curettage, hysteroscopy, hysterectomy, etc. ${ }^{9}$ Hence, this study was conducted to measure the prevalence of thyroid disorders and evaluate its correlation with menstrual disorders in reproductive age group women.

\section{METHODS}

This prospective cross-sectional study was conducted in the department of Obstetrics and Gynecology of Nalanda Medical College and Hospital, Patna over a period of 1 year from March 2017 to March 2018, after taking permission from hospital ethics committee. Confidentiality was maintained and verbal consent was taken from each patient before enrolling in the study.

\section{Inclusion criteria}

A total 56 women of reproductive age group between 18 to 45 years presenting in OPD with menstrual disorders (like menorrhagia, oligomenorrhea/hypomenorrhea, polymenorrhea, metrorrhagia, and amenorrhea) were included in this study.

\section{Exclusion criteria}

Patients with previously known thyroid disorder, History of abortion within 3 months, History of childbirth within 1 year, IUCD or OCP users, Patients with known liver disorders or coagulopathy, Patients with known organic pathology like uterine fibroid, adenomyosis, endometrial tuberculosis, polyp, uterine malignancy, etc., medical comorbidity precluding study, like uncontrolled HTN, DM, Patients not willing to give consent

A detailed history about age and bleeding pattern, onset, duration, amount of bleeding and problems related to thyroid dysfunction were noted. Amount of bleeding was judged from number of pads soaked and clots passed. Relevant clinical examination including general physical examination, systemic and gynecological examination was done, with special reference to thyroid dysfunction. Patients having clinical signs and symptoms of thyroid disease were excluded from the study. Routine investigations like $\mathrm{Hb}$, Platelet count, TLC, DLC, ESR, ABO-Rh, LFT, RBS, bleeding and clotting time, complete urine examination, and thyroid profile that includes T3, T4 and TSH was performed in all patients. Serum T3, T4 and TSH was estimated by direct quantitative determination by ELISA using human serum-based calibration. They were also subjected to special investigations like chest $\mathrm{x}$-ray, ultrasound abdomen and pelvis, pap smear, endometrial sampling, and hysteroscopy (wherever indicated). Reference values taken were: TSH level $=0.39-6.16 \mu \mathrm{IU} / \mathrm{ml}$, Free T3 level=1.4-4.2 pg/ml and Free T4 level=0.8-2.0 ng/ml. Patients were categorized into five groups as follows (Table 1).

Table 1: Groups of patients.

\begin{tabular}{|llll|}
\hline Diagnosis & TSH & Free T3 & Free T4 \\
\hline Euthyroid & Normal & Normal & Normal \\
\hline $\begin{array}{l}\text { Subclinical } \\
\text { hypothyroidism }\end{array}$ & Elevated & Normal & Normal \\
\hline $\begin{array}{l}\text { Overt } \\
\text { hypothyroidism }\end{array}$ & Elevated & Low & Low \\
\hline $\begin{array}{l}\text { Subclinical } \\
\text { hyperthyroidism }\end{array}$ & Low & Normal & Normal \\
\hline $\begin{array}{l}\text { Overt } \\
\text { hyperthyroidism }\end{array}$ & Low & Elevated & Elevated \\
\hline
\end{tabular}

\section{Statistical analysis}

Data were entered into an excel spreadsheet and analyzed using SPSS version 16.0. Descriptive statistics presented as (mean \pm standard) deviation and frequencies as percentages. Pearson correlation coefficient (r) was used to determine correlation between thyroid dysfunction and menstrual disorders. Value of 1 implies total positive linear correlation, 0 is no linear correlation, and -1 is total negative linear correlation.

\section{RESULTS}

Total 56 women with menstrual disorders were included in this study with mean age of $31.33 \pm 7.25$ years. Majority of cases $(44.64 \%)$ belonged to the age group between 31 to 40 years and least of them $(7.14 \%)$ belonged to $\leq 20$ years age. $37.5 \%$ were between age group of 21-30 years and $10.71 \%$ were above 40 years of age (Table 2 ).

Table 2: Age distribution of study population

\begin{tabular}{|lll|}
\hline Age group (year) & No. of cases & Percentage \\
\hline$\leq \mathbf{2 0}$ & 4 & 7.14 \\
\hline $\mathbf{2 1 - 3 0}$ & 21 & 37.5 \\
\hline $\mathbf{3 1 - 4 0}$ & 25 & 44.64 \\
\hline $\mathbf{4 0}$ & 6 & 10.71 \\
\hline Total & 56 & 100 \\
\hline
\end{tabular}


Table 3: Distribution of patients according to parity.

\begin{tabular}{|lll|}
\hline Parity & No. of cases & Percentage \\
\hline Unmarried & 6 & 10.71 \\
\hline Nullipara & 5 & 8.93 \\
\hline Para 1 & 8 & 14.29 \\
\hline Para 2 & 15 & 26.79 \\
\hline Para 3 & 10 & 17.86 \\
\hline Para $\geq \mathbf{4}$ & 12 & 21.42 \\
\hline Total & 56 & 100 \\
\hline
\end{tabular}

Table 4: Distribution of patients according to menstrual disorders.

\begin{tabular}{|lll|}
\hline Presenting complaints & No. of cases & Percentage \\
\hline Menorrhagia & 26 & 46.42 \\
\hline Metrorrhagia & 9 & 16.08 \\
\hline Polymonorrhea & 6 & 10.71 \\
\hline Hypo/Oligomenorrhea & 10 & 17.86 \\
\hline Amenorrhoea & 5 & 8.93 \\
\hline Total & 56 & 100 \\
\hline
\end{tabular}

Table 5: Distribution of patients according to thyroid function test.

\begin{tabular}{|lll|}
\hline Thyroid status & No. of cases & Percentage \\
\hline Euthyroid & 33 & 58.93 \\
\hline Hypothyroid & & \\
\hline Subclinical & 10 & 17.86 \\
\hline Overt & 7 & 12.5 \\
\hline Hyperthyroid & & \\
\hline Subclinical & 3 & 5.35 \\
\hline Overt & 3 & 5.35 \\
\hline Total & 56 & 100 \\
\hline
\end{tabular}

Among 56 cases, maximum number of patients were para $2(26.79 \%)$ followed by para 4 and above $(21.42 \%)$, and nulliparas $(8.93 \%)$ were least in number. Six $(10.71 \%)$ patients were unmarried and $14.29 \%$ cases were para 1 (Table 3). Out of all types of menstrual irregularities, maximum patients were having complaints of menorrhagia (46.42\%) followed by hypo/oligomenorrhoea $(17.86 \%)$ and minimum were seen with amenorrhoea $(8.93 \%)$. Metrorrhagia was seen in 9 $(16.08 \%$ ) patients and polymenorrhea in $10.71 \%$ (Table 4).

Table 6: Bleeding patterns in relation to different thyroid status.

\begin{tabular}{|llllll|}
\hline Variables & Euthyroid & Hypothyroid & Hyperthyroid \\
\hline Bledding pattern & $\mathbf{N}(\boldsymbol{\%})$ & Subclinic $(\boldsymbol{\%})$ & Overt $(\%)$ & Subclinic $(\%)$ & Overt $(\%)$ \\
\hline Menorrhagia $(\mathrm{n}=26)$ & $17(65.38)$ & $5(19.23)$ & $4(15.38)$ & 0 & 0 \\
\hline Metrorrhagia $(\mathrm{n}=9)$ & $7(77.78)$ & $2(22.22)$ & 0 & 0 & 0 \\
\hline Polymenorrhea $(\mathrm{n}=6)$ & $3(50)$ & $2(33.33)$ & $1(16.67)$ & 0 & 0 \\
\hline Hypo/Oligomenorrhea $(\mathrm{n}=10)$ & $5(50)$ & $1(10)$ & $1(10)$ & $1(10)$ & $2(20)$ \\
\hline Amenorrhoea $(\mathrm{n}=05)$ & $1(20)$ & 0 & $1(20)$ & $2(40)$ & $1(20)$ \\
\hline Total $(\mathbf{n = 5 6 )}$ & 33 & 10 & 7 & 3 & 3 \\
\hline
\end{tabular}

Table 7: Correlation of thyroid dysfunction with menstrual disorders.

\begin{tabular}{|lllllll|}
\hline Presenting complaints & No. & Percentage & Thyroid status & No. & Percentage \\
\hline Menorrhagia $(\mathbf{n = 2 6})$ & 26 & 46.42 & Euthyroid & Overt hypothyroid & 7 & 58.93 \\
\hline Metrorrhagia $(\mathbf{n = 9})$ & 9 & 16.08 & Subclinical hypothyroid & 10 & 12.5 \\
\hline Polymenorrhea $(\mathbf{n = 6})$ & 6 & 10.71 & Overt hypothyroid & 3 & 5.35 \\
\hline Hypo/Oligomenorrhea $(\mathbf{n = 1 0})$ & 10 & 17.86 & Subclinical Hypothyroid & 3 & 5.35 \\
\hline Amenorrhoea $(\mathbf{n = 5 6})$ & 5 & 8.93 & $0.93 *$ \\
\hline
\end{tabular}

*Pearson correlation (r) shows high degree positive correlation between thyroid dysfunction and menstrual disorders

Total $58.93 \%$ of women $(n=33)$ were found to be euthyroid and rest $41.07 \%(n=23)$ were associated with some or other forms of thyroid dysfunction (Table 5). Hypothyroidism was the commonest abnormality as seen in $30.36 \%$ cases, out of which $17.86 \%$ had subclinical hypothyroidism and $12.5 \%$ had overt hypothyroidism. $10.71 \%$ of patients $(n=6)$ had hyperthyroidism $(5.35 \%$ of subclinical hyperthyroid and overt hyperthyroid each), although they were clinically asymptomatic.

Menorrhagia was the most common presenting complaint $(46.42 \%)$. Majority of patients with menorrhagia were euthyroid (65.38\%) while five cases (19.23\%) had subclinical hypothyroidism and four cases $(15.38 \%)$ had overt hypothyroidism. Among the patients with hypo/oligomenorrhea, one case $(10 \%)$ had subclinical hypothyroidism, overt hypothyroidism and subclinical hyperthyroidism each, two cases $(20 \%)$ had overt hyperthyroidism, and rest (50\%) were euthyroid.

Among the patients with metrorrhagia, two cases $(22.22 \%)$ had subclinical hypothyroidism and $77.78 \%$ had euthyroid. $33.33 \%$ patients among polymenorrhea had subclinical hypothyroidism while $16.67 \%$ had overt hypothyroidism. Among the patients with amenorrhea, 
two cases $(40 \%)$ had subclinical hyperthyroidism and one case (20\%) had overt hypothyroidism and hyperthyroidism each (Table 6).

As seen in Table 7, a high degree of positive correlation was observed between thyroid dysfunction and menstrual disorders (Pearson correlation coefficient, $r=0.93$ )

\section{DISCUSSION}

Thyroid disorders particularly hypothyroidism are the common causes of menstrual disorders in women. All phases in women's life from menarche, pubertal growth and development, fertility and fetal development, and reproduction to menopause are profoundly influenced by the thyroid status. It is recognized that menstrual disturbances may accompany and even may precede thyroid dysfunction. ${ }^{1}$

Nowadays precise estimation of thyroid hormones in serum in a rapid and reliable manner is possible with the advent of modern hormonal assay techniques. Treatment of hypothyroidism is very satisfying as it usually relieves all the symptoms of patients. Hence, evaluation of thyroid functional status forms an essential component in investigating a patient with menstrual irregularities. Early detection of hypothyroidism can save the patient from surgical interventions like recurrent curettage and at times hysterectomy. ${ }^{11}$

In our study, most of the patients with menstrual disorders were in the age group of 31 to 40 years (44.64 $\%$ ) followed by $37.5 \%$ in the age group of 21 to 30 years. Gandi in their study also found maximum number patients in the age group of 31 to 40 years (49\%) followed by 21 to 30 years $(37 \%) .^{2}$ Bhavani in their study reported that majority of patients were in the age group of 31 to 40 years $(37 \%) .^{12}$

In the present study, most of the menstrual disorders are seen in multiparous women $(66.07 \%)$, followed by primipara $(14.29 \%)$ and nullipara $(8.93 \%)$. Similar findings were seen in Gandi study. ${ }^{2}$ In Byna study, $18 \%$ patients were primiparas, $54 \%$ were para 2 and $27 \%$ were para 3 and above. ${ }^{13}$ Women sterilization after two children may be the cause of higher number of para 2 women.

Menorrhagia was the most common bleeding pattern among the patients with menstrual disorders in our study $(46.42 \%)$. Similar observations were seen in Pahwa (50\%) and Padmaleela (50\%) study, where menorrhagia was the most common complaint. ${ }^{14,15}$ Other menstrual disorder common in this study was hypo/oligomenorrhoea (17.86\%), which was nearly similar to the observation by Ajmani study (20\%). ${ }^{1}$

In this study, we observed that $41.07 \%$ of patients with menstrual disorders were diagnosed with some form of thyroid dysfunction of which $17.86 \%$ had subclinical hypothyroidism, $12.5 \%$ had overt hypothyroidism and $5.35 \%$ had overt hyperthyroidism and subclinical hyperthyroidism each. Euthyroid was seen in $58.93 \%$ patients. Ajmani in their study reported $20 \%$ cases as subclinical hypothyroidism, $14 \%$ as overt hypothyroidism, $2 \%$ subclinical hyperthyroidism and $8 \%$ overt hyperthyroidism and $56 \%$ as euthyroid. ${ }^{1}$ Our findings were different from that of Sangeeta study which reported that $22 \%$ of cases were hypothyroid, $2 \%$ hyperthyroid and $76 \%$ were euthyroid. ${ }^{14}$ In our study amongst those with thyroid dysfunction, there were $43.48 \%$ cases of subclinical hypothyroidism while $30.43 \%$ were overt hypothyroidism. These results were consistent with the study of Ajmani (45.45\% subclinical hypothyroid and $31.82 \%$ overt hypothyroid) and Gandi (45.45\% subclinical hypothyroid and $25 \%$ overt hypothyroid) but different from George $(55.90 \%$ subclinical hypothyroid and $10.1 \%$ overt hypothyroid) and Maria (66.40\% subclinical hypothyroid) study. ${ }^{1,2,16,17}$

Commonest menstrual abnormality in hypothyroid (including both subclinical and overt) patients in our study was menorrhagia $(52.94 \%)$ followed by polymenorrhea $(17.65 \%)$, hypo/oligomenorrhea and metrorrhagia ( $11.76 \%$ each). In a study, Kaur found that among 14 hypothyroid patients, $64.3 \%$ patients had menorrhagia, $21.4 \%$ had oligomenorrhea and $14.28 \%$ had metrorrhagia. ${ }^{18}$ Commonest menstrual problem in Padmaleela study was menorrhagia $(53.3 \%)$ which was followed by hypo/oligomenorrhea (20\%) and polymenorrhea $(13.3 \%)$ in hypothyroid patients. ${ }^{15}$ In a study done by Wilansky $100 \%$ cases had menorrhagia in hypothyroidism. ${ }^{19}$ In Sudha study, commonest menstrual abnormality seen in hypothyroidism was polymenorrhoea $(32.25 \%)$ while polymenorrhagia and menorrhagia was seen in $29.03 \%$ cases each. ${ }^{20}$ Among six hyperthyroid patients (including both overt and subclinical hyperthyroidism) of this study, hypo/oligomenorrhea and amenorrhea were equally seen in $50 \%$ cases. In the study by Padmaleela, among the hyperthyroid patients, $42.8 \%$ had menorrhagia, $28.6 \%$ had polymenorrhea, and $14.3 \%$ had hypo/oligomenorrhea. ${ }^{15}$ Pahwa found that of two hyperthyroid patients, both had menorrhagia. ${ }^{14}$ All patient of hyperthyroidism in Kaur study had hypomenorrhea. ${ }^{18}$.

\section{CONCLUSION}

From this study, it may be concluded that there is a strong correlation of thyroid dysfunction with menstrual disorders. So, thyroid function test should be done in all women with menstrual disorders. If thyroid disorders are timely diagnosed and treated in patients with menstrual disorders, the menstrual irregularities will settle and unnecessary intervention like hormonal treatment and surgery can be avoided. Knowing the high prevalence of subclinical hypothyroidism in patients with menstrual disorders emphasis should be given to detect the hypothyroidism at this stage, so that treatment can be initiated and progression to overt disease be prevented. 


\section{Limitation}

Limitations were this was a single hospital based study with small sample size, hence results of this study may not be generalized to general population but still be useful in preparation of a good database for future studies and other uses and unless a proper evaluation function tests are done among these patients, we are bound to miss the etiology of menstrual disorders leading to nonspecific and ineffective procedures and treatments.

Funding: No funding sources

Conflict of interest: None declared

Ethical approval: The study was approved by the Institutional Ethics Committee

\section{REFERENCES}

1. Sangita AN, Sarbhai V, Yadav N, Paul M, Ahmad A, Ajmani AK. Role of thyroid dysfunction in patients with menstrual disorders in tertiary care center of walled city of Delhi. J Obst Gynecol India. 2016;66(2):115-9.

2. Gandi SR, Vishwekar P, Yadav RS, Chauhan N. Study of thyroid dysfunction in women with menstrual disorders: A prospective study. MedPulseInt J Gynaecol. 2019;9(3):89-93.

3. Poppe K, Glinoer D. Thyroid autoimmunity and hypothyroidism before and during pregnancy. Human Reprod Update. 2003;9:149-61.

4. Kochupillai N. Clinical endocrinology in India. Curr Sci. 2000;79:1061-7.

5. Hollowell JG, Staehling NW, Flanders WD, et al. Serum TSH, T4, and thyroid antibodies in the United States population (1988 to 1994): National Health and Nutrition Examination Survey (NHANES III). J Clin Endocrinol Metab. 2002;87(2):489-99.

6. Gowri M, Radhika BH, Harshini V, Ramaiaha R. Role of thyroid function tests in women with abnormal uterine bleeding. Int J Reprod Contracept Obstet Gynecol. 2014;3(1):54-7.

7. Sharma N, Sharma A. Thyroid profile in menstrual disorders. JK Science. 2012;14(1):14-7.

8. Abraham R, Murugan VS, Pukazhvanthen P. Thyroid disorders in women of puducherry. Indian J Clin Biochem. 2009;24(1):52-9.

9. Thomas R, Reid RL. Thyroid disease and reproductive dysfunction: a review. Obstet Gynecol. 1987;70:789-98.
10. Kakuno Y, Amino N, Kanoh M. Menstrual disturbances in various thyroid disease. Endocr $\mathrm{J}$. 2010;57(12):1017-22.

11. Deshmukh PY, Boricha BG, Pandey A. The association of thyroid disorders with abnormal uterine bleeding. Int $\mathbf{J}$ Reprod Contracept Obstet Gynecol. 2015;4:701-8.

12. Bhavani N, Avanti S, Arad HG, Sangeeta C, Prannakumar VS. A study of correlation between abnormal uterine bleeding and thyroid dysfunction. Int J Recent Trends Sci Technol. 2015;14(1):131-5.

13. Byna P, Siddula S, Kolli S, Shaik MV. Thyroid abnormality in perimenopausal women with abnormal uterine bleeding. Int $\mathrm{J}$ Res Med Sci. 2015;3:3250-3.

14. Pahwa S, Shailja G, Jasmine K. Thyroid dysfunction in dysfunctional uterine bleeding. J Adv Res Bio Sci. 2013;5(1):78-83.

15. Padmaleela K, Thomas V, Lavanya KM. Thyroid disorders in dysfunctional uterine bleeding (DUB) among reproductive age group women- a crosssectional study in a tertiary care hospital in Andhra Pradesh India. Int J Med Pharma Sci. 2013;4(1):416.

16. George L, Jacob KJ, Shankar SB. The role of thyroid hormone status in abnormal uterine bleeding. J Evol Med Dent Sci. 2017;6(76):5448-51.

17. Maria JD, Jayakumari S, Sundaram PS. A prospective study on hypothyroidism in premenopausal women. Int $\mathbf{J}$ pharm Sci Rev Res. 2016;39(1):183-7.

18. Kaur T, Aseeja V, Sharma S. Thyroid dysfunction in dysfunctional uterine bleeding. Web Med Central Obstet Gynaecol. 2011;2(9):1-7.

19. Wilansky DL, Greisman B. Early hypothyroidism in patients with menorrhagia. Am J Obstet Gynecol. 1989;160(3):673-7.

20. Sudha HC, Sunanda KM, Anitha GS. Abnormal uterine bleeding in relation to thyroid dysfunction. Int J Reprod Contracept Obstet Gynecol. 2018;7:4525-30.

Cite this article as: Kumari A, Rohatgi R, Singh A. Evaluation of thyroid dysfunction in patients with menstrual disorders of reproductive age group: A prospective cross-sectional study. Int J Reprod Contracept Obstet Gynecol 2021;10:642-6. 